\title{
ANÁLISIS BÁSICOS DE AGUAS PARA FINES ACUÍCOLAS
}

Wilfredo Noel Guevara', Reyna Calcino Angulo

\section{INTRODUCCIÓN}

El presente manual no tiene la pretensión de enseñar más de lo que se conoce; su objetivo esencial es el de facilitar el trabajo de laboratorio y contribuir a establecer el mejor equilibrio entre la rapidez, por un lado, y la perfección y exactitud por otro.

El presente, es el resultado de la adecuación de técnicas que en forma experimental se han llevado a cabo en nuestros laboratorios y esperamos que sea un aporte para contribuir al conocimiento de las técnicas existentes y sirva de ayuda a las personas y profesionales que se dediquen al estudio acuícola.

\section{RECOMENDACIONES}

Las determinaciones físico-químicas del agua deben realizarse observando las siguientes recomendaciones:

1. Temperatura ideal para los análisis.

2. Usar equipos, material de laboratorio apropiado y reactivos químicos de garantía.

3. Realizar los análisis necesarios para conocer la calidad del agua.

4. Para obtener resultados veraces sobre ciertos constituyentes y valores físicos, se requiere análisis inmediatos en el campo, porque la composición de la muestra puede variar antes de llegar al laboratorio.

5. Conservar la muestra en la oscuridad y a baja temperatura hasta que se analice, se sugieren como tiempos límites máximos para muestras destinadas a análisis:

Aguas no contaminadas

Aguas ligeramente contaminadas

Aguas contaminadas

72 horas.

48 horas.

12 horas.

1. Ingeniero Pesquero

2. Bachiller en quimica.

6. Realizar los análisis químicos por duplicado si se dispone de suficiente tiempo, personal y reactivos. ÍNDICE

01. Determinación de la Temperatura.

02. Determinación de la Visibilidad.

03. Determinación de la Conductividad Eléctrica.

04. Determinación del Oxígeno Disuelto.

05. Determinación del Bióxido de Carbono Libre.

06. Determinación de la Alcalinidad.

07. Determinación del $\mathrm{pH}$.

08. Demanda Bioquímica de Oxígeno (DBO).

09. Demanda Quimica de Oxígeno (DQO).

10. Determinación de Dureza.

11. Determinación de Calcio.

12. Determinación de Nitratos.

13. Determinación de Amonio.

14. Determinación de Cloruros.

15. Determinación de Sodio y Potasio.

16. Determinación de Ortofosfátos.

EXÁMENES FÍSICOS Y QUIMICOS DEL AGUA TEMPERATURA DEL AGUA

\section{Introducción}

La temperatura es el factor que más influye en el medio acuático, tiene acción decisiva en la distribución de los seres vivos dentro del medio en que viven, influye en los factores abióticos (estratificación, disociación de iónes, etc.) como en los bióticos (velocidad de reacciones químicas en función a la temperatura, etc).

El metabolismo y la reproducción de los seres acuáticos se aceleran más en las aguas calientes que en las frias i, por lo tanto, es el primer factor en la productividad biológica de las aguas.

\section{a. Temperatura Superficial}

La medición de la temperatura superficial se hará mediante el termómetro simple protegido, graduado cada $0.1^{\circ} \mathrm{C}$ y con un rango de $0^{\circ} \mathrm{C}$ a 40 
${ }^{\circ} \mathrm{C}$, éste deberá ser calibrado previamente frente al termómetro de inversión.

Para casos en que se trabaja evaluando cuerpos de agua como alternativas para la instalación de centros de producción acuícola, las tomas de temperatura se deberán hacer en periodos continuos durante 24 horas cada treinta dias, especialmente en la época más fria y cálida de la región. Para evitar pérdidas, se debe asegurar el termómetro al cuello del observador.

\section{b.Temperatura sub-superficial}

El registro de temperatura sub-superficial se hará efectivo mediante el uso del termómetro de inversión.

\section{TERMÓMETRO DE INVERSIÓN}

Aunque antiguo, es uno de los más exactos y es muy útil para la determinación de la tempertura sub-superficial.

Consiste de un termómetro de mercurio armado en un marco de metal, se baja el termómetro con un cable marcado hasta la profundidad deseada, donde se le deja unos 5 minutos. Despúes de este tiempo el termómetro indica la temperatura del lugar de exposición y se baja un mensajero por el cable marcado, que hace girar el termómetro 180 grados en el marco de metal.Al girar el termómetro, el hilo de mercurio se quiebra en un estrechamiento del tubo capilar y baja al otro extremo de éste, que ahora se encuentra por abajo. Como el hilo de mercurio está desconectado al reservorio ya no puede influir en su longitud un posible cambio de temperatura al subir el termómetro.Con la división del tubo capilar en 0.1 ${ }^{\circ} \mathrm{C}$, ahora se puede leer la temperatura con gran exactitud.

Para usar el termómetro nuevamente, se deben unir las dos partes del mercurio, volteando el termómetro 180 grados y calentando el reservorio de mercurio hasta que se fundan las dos partes separadas.

\section{TERMÓMETROS ELÉCTRICOS}

Son los más usados en la actualidad, y tienen la ventaja de indicar la temperatura al instante. Constan de 03 partes principales:

- El Termoelemento, que es expuesto a la profundidad deseada.

- El cable que conecta al termoelemento con el instrumento de medición.
- El puente de Wheatstone y el instrumento indicador de lectura.

Antes de usar este termómetro, debe ser calibrado con un termómetro de mercurio patrón.

El tiempo empleado con este termómetro para un perfil es mínimo.

\section{TRANSPARENCIA (VISIBILIDAD)}

La transparencia es una medida de la profundidad a la cual uno puede ver dentro del agua. Por supuesto esto es variable con la cantidad de materia orgánica (viva o inerte) e inorgánica en suspensión,con las condiciones del dia, con la vista del observador, con el color del lecho, etc.

La densidad del plancton y la materia en suspensión hacen variar el grado de transparencia, mientras mayores son éstas menor será la transparencia y viceversa.

Para medir la transparencia (visibilidad), se usa el Disco de Secchi, que consiste en un plato circular de $35 \mathrm{~cm}$ de diametro dividido en cuadrantes, dos de los cuales (opuestos) son pintados de blanco y los otros dos de negro. Este atado a una soguilla graduada en centímetros.

\section{Equipos y materiales}

- Disco de Secchi de metal de $35 \mathrm{~cm}$ de diámetro, pintado de blanco y negro alternativamente.

- Cabo graduado en intervalos de $10 \mathrm{~cm}$.

- Una regla graduada de $15 \mathrm{~cm}$.

\section{Procedimiento}

Introducir el Disco de Secchi en el agua hasta que el dispositivo desaparezca totalmente de la vista del operador (anotar lectura), luego izándolo inmediatamente anotar la profundidad en que reaparece el disco.

El promedio de ambas lecturas señalará el limite de visibilidad (transparencia) en centímetros.

\section{Recomendaciones para medición de transparencia}

- Que la agitación del agua sea mínima.

- La lectura deberá efectuarse en el lado protegido de la embarcación.

- La toma de la transparencia se hará en el lado sombreado (de espaldas al sol).

- El ojo del observador debe estar a una distancia fija encima de la superficie del agua (aprox. $30 \mathrm{~cm}$ ). 
- Las observaciones se realizarán al mediodía o a primeras horas de la mañana.

- Registrar en lo posible el grado de agitación de la superficie del agua.

- Registrar tambien las características cualitativas del estado del tiempo (nubosidad, precipitación, intensidad del sol, etc).

- Para datos de transparencia en cuerpos lóticos, expresar los resultados en términos porcentuales con relación a la profundidad en el momento del muestreo.

\section{CONDUCTIVIDAD ELÉCTRICA}

\section{Introducción}

Es una determinación rápida y precisa de la concentración total de constituyentes ionizados en el agua. Esta concentración es medida a través de la Conductividad Eléctrica entre dos electrodos separados por $01 \mathrm{~cm}$ y con un área de $01 \mathrm{~cm}$ cuadrados.

\section{Reactivos}

- Solución patrón de Cloruro de potasio $0.01 \mathrm{~N}$.

Esta es la solución patrón de referencia que a $25^{\circ} \mathrm{C}$ tiene una conductividad eléctrica de $1411.8 \mathrm{micromhos} / \mathrm{cm}$.

\section{Equipo}

- Conductímetro.

\section{Procedimiento}

1. Prender el conductímetro.

2. Medir la temperatura de la muestra.

3. Llenar la celda de conductividad con una alícuota de muestra.

4. Leer en la escala del conductimetro la conductividad en micromhos/cm.

5. Después de cada lectura debe lavarse la celda con agua destilada.

\section{Cálculos}

Corrección en función de la temperatura: la conductividad de un líquido depende en gran medida de la temperatura. Esta temperatura se tomará exactamente en el curso de la medida, y si no se realiza a $25^{\circ} \mathrm{C}$, efectuar la corrección según la fórmula:

$$
\text { Conductividad } 25^{\circ} \mathrm{C}=\mathrm{Ct} \times \mathrm{Ft}
$$

Siendo:

Ft: Factor de corrección de temperatura, dado en tablas.

Ct: Lectura de Conductividad a una temperatura dada.

\section{MÉTODOS QUÍMICOS}

Dado que existen un buen número de descripciones publicados sobre los análisis químicos del agua, se hablará sobre los métodos más importantes, necesarios y básicos a realizar en un cuerpo de agua sujeto a evaluación o de cultivo.

\section{DETERMINACIÓN DEL CONTENIDO DE OXÍGENO DISUELTO EN EL AGUA}

\section{MÉTODO VOLUMÉTRICO DE WINKLER}

\section{Principio}

El oxígeno disuelto al combinarse con el Hidróxido Manganoso ( $\mathrm{MnOH} 2)$, forma hidróxidos más fuertes, que al ser acidificados en presencia de I, liberan 12, en una cantidad equivalente al contenido de oxígeno disuelto en la muestra. EI 12 es por consiguiente determinado por titulación con Tiosulfato de Sodio.

\section{Reactivos}

1. Sulfato Manganoso: $480 \mathrm{~g}$ de MnSO $4.4 \mathrm{H} 2 \mathrm{O}$ ó 400 g. de $\mathrm{MnSO} 4.2 \mathrm{H} 2 \mathrm{O}$.

Disolver en agua destilada y completar a un litro.

2. Solución íoduro Alcalina: disolver $500 \mathrm{~g}$. de $\mathrm{NaOH}$ (ó $700 \mathrm{~g}$ de $\mathrm{KOH}$ ) y $135 \mathrm{~g}$. de Nal (ó $150 \mathrm{~g}$. de $\mathrm{KI}$ ) en agua destilada y completar a I,0 litro.

3. Acido Sulfúrico concentrado (H2SO4: p.e. I,831,84).

4. Solución de Tiosulfato N/40: disolver en agua destilada recién hervida y enfriada, $6.205 \mathrm{~g}$ de Tiosulfato de Sodio ( $\mathrm{Na} 2 \mathrm{~S} 2 \mathrm{O} 3.5 \mathrm{H} 2 \mathrm{O}$ ) y completar a 1.0 litro. Adicionar $5 \mathrm{cc}$ de Cloroformo como preservador. La solución se debe estandarizar a intervalos de 30 dias con una solución de Dicromato de Potasio $0.025 \mathrm{~N}$.

5. Solución de almidón (indicador): Añadir 1 gramo de almidón soluble a $100 \mathrm{ml}$ de agua. Calentar hasta obtener una solución transparente. Agregar $0.5 \mathrm{ml}$ de formol. Esta solución es estable por 30 dias.

\section{Procedimiento}

1. Tomar la muestra de agua en una botella de 250 cc. con tapa esmerilada. Agregarle $1 \mathrm{cc}$ de Sulfato manganoso , $1 \mathrm{cc}$ de solución ioduro alcalina y 
agitar invirtiendo varias veces la botella. Dejar que el precipitado blanco se asiente en el fondo.

2. Adicionar $1 \mathrm{cc}$ de ácido sulfúrico concentrado y mezclar bien la muestra, invirtiendo varias veces la botella. De esta manera el oxígeno ha sido fijado y puede durar varias horas la muestra.

3. Transferir $200 \mathrm{cc}$ a un erlenmeyer y Titular con Tiosulfato de sodio, hasta que el color se torne a un amarillo pálido.

4. Adicionar 2 cc de almidón que le va a dar una coloración azul a la muestra.

5. Seguir titulando con el tiosulfato de sodio hasta que el color azul desaparezca, dándose por terminado el análisis.

\section{Cálculo de los resultados}

$$
\mathrm{O} 2 \mathrm{mg} / \mathrm{l}=\frac{\text { Gasto tiosulfato } \times \mathrm{N} \times 8000}{\mathrm{ml} \mathrm{M.} \mathrm{titulada} \times \frac{\mathrm{ml} \mathrm{Frasco-3}}{\mathrm{ml} \text { frasco }}}
$$

Los resultados en términos de porcentaje de saturación son obtenidos dividiendo el valor de la titulación en cc. por el valor de solubilidad, determinado por la temperatura de la muestra que se expresa en tablas de libros de Limnología.

\section{DETERMINACIÓN DEL BIÓXIDO DE CARBONO LIBRE EN EL AGUA}

\section{Principio}

El CO2 libre reacciona con el $\mathrm{Na} 2 \mathrm{CO} 3$ o con el $\mathrm{NaOH}$ para formar $\mathrm{NaHCO}$. El punto final de la titulación es dado por la formación del color rosa característico del indicador Fenoltaleína ( $\mathrm{pH}$ equivalente a 8.3).

\section{Reactivos}

1. Indicador de Fenoltaleína: disolver $5 \mathrm{~g}$ de fenoltaleina en 1 litro de alcohol al $50 \%$. Neutralizar con $\mathrm{NaOH} \mathrm{N} / 50$.

2. Solución de $\mathrm{NaOH} \mathrm{N} / 44$ : pesar $0.900 \mathrm{~g}$ de NaOH y diluir a un litro con agua destilada, recientemente hervida y enfriada.

\section{Procedimiento}

1. Tomar $100 \mathrm{cc}$ de muestra en un tubo de Nessler con el mismo cuidado que para el Oxígeno disuelto.

2. Adicionar 10 gotas de fenoltaleina.

3. Titular con $\mathrm{NaOH} \mathrm{N} / 44$, hasta que el color rosado permanezca por lo menos 30 segundos.

\section{Cálculos}

$\mathrm{CO} 2 \mathrm{ppm}=\frac{\text { Gasto } \mathrm{ml} \times \mathrm{Fc} \times \mathrm{N} \times 44 \times 1000}{\text { Volumen de muestra }}$

Donde : Gasto $\mathrm{ml}$ : Gasto del $\mathrm{NaOH}$.

Fc : Factor de corrección del $\mathrm{NaOH}$.

$\mathrm{N}$ : Normalidad del $\mathrm{NaOH}$.

\section{DETERMINACIÓN DE LA ALCALINIDAD}

La alcalinidad en muchas aguas naturales es debida a los carbonatos presentes, bicarbonatos e hidróxidos. Usando 2 indicadores y un ácido fuerte, estas tres fuentes de alcalinidad pueden ser diferenciadas y medidas.

\section{Materiales}

- Frasco erlenmeyer de $250 \mathrm{ml}$.

- Pipeta de $5 \mathrm{ml}$.

- Fiolas.

- Bureta de $10 \mathrm{ml}$.

\section{Reactivos}

1. Indicador de Fenoltaleína. (Ver determinación de CO2 libre).

2. Indicador de anaranjado de metilo: disolver $0,5 \mathrm{~g}$ de anaranjado de metilo de alta calidad en 1 litro de agua destilada. Guardar en frasco oscuro.

3. $\mathrm{H} 2 \mathrm{SO} 4 \mathrm{~N} / 50(0.02 \mathrm{~N})$ : transferir $10 \mathrm{ml}$ de ácido sulfúrico concentrado a un frasco volumétrico y hacer hasta 1 litro con agua destilada.La solución resultante es aproximadamente $0,36 \mathrm{~N}$. Para hacer una solución $\mathrm{N} / 50$ : de la solución de reserva transferir $55,36 \mathrm{ml}$ a un frasco volumétrico con una bureta y completar a 1 litro.

\section{Procedimiento}

1. Transferir $100 \mathrm{ml}$ de la muestra de agua a un erlenmeyer.

2. Agregar 4 gotas del indicador de Fenoltaleína.

3. Si la muestra permanece clara, registrar como alcalinidad 0,0 de fenoltaleina y proceder con el paso 5 .

4. Si la muestra se vuelve rosada, titular con $\mathrm{H} 2 \mathrm{SO} 4$ $\mathrm{N} / 50$, con una bureta, hasta el momento preciso que el color rosa desaparece. La titulación debe hacerse contra un fondo blanco a los efectos de una mejor percepción del color. Registrar la cantidad de ácido utilizada como $\mathrm{P}$.

5. A la misma muestra agregar 4 gotas de indicador 
de anaranjado de metilo.

6. Si la muestra se vuelve naranja (o color salmón), registrar como alcalinidad de anaranjado de metilo 0,0 .

7. Si la muestra se vuelve amarilla, titular con $\mathrm{H}_{2} \mathrm{SO} 4$ $\mathrm{N} / 50$, hasta que se vuelva ligeramente anaranjada. Registrar la cantidad utilizada como M.

\section{Cálculos}

\section{Símbolos y términos}

$\mathrm{P}=$ Número de $\mathrm{ml}$ de $\mathrm{H} 2 \mathrm{SO} 4 \mathrm{~N} / 50$, utilizado en la titulación con Fenoltaleína.

$\mathrm{M}=$ Número de $\mathrm{ml}$ de $\mathrm{H} 2 \mathrm{SO} 4 \mathrm{~N} / 50$, utilizado en la titulación con anaranjado de metílo.

$\mathrm{T}=$ Suma de $\mathrm{P}$ y $\mathrm{M}$ (número total de $\mathrm{ml}$ de $\mathrm{H} 2 \mathrm{SO} 4$ $\mathrm{N} / 50$, utilizados en la titulación total).

En el cálculo que se sigue se usa solamente $P$ y T. De estos, uno puede determinar y expresar en ppm de carbonatos de calcio, ya sea:

Alcalinidad a la fenoltaleina $=P \times 10$

Alcalinidad al anaranjado de metílo $=M \times 10$ (también conocida como alcalinidad total).

\section{Conversiones e interpretación de relaciones de alcalinidad}

\section{a)Conversión a SBV (Saurebindungsvemongen)}

Conocida indistintamente como poder de combinación de ácidos, reservas alcalinas, etc., se expresa sencillamente como el número total de $\mathrm{ml}$ de $\mathrm{HCl} \mathrm{N} / 10$ o $\mathrm{H} 2 \mathrm{SO} 4$, requerido para titular 100 $\mathrm{ml}$ de una muestra de agua utilizando anaranjado de metilo como indicador.

Para convertir el total o la Alcalinidad del anaranjado de metilo (expresada en ppm de $\mathrm{CO} 3 \mathrm{Ca}$ ) multiplicar por 50.

\section{DETERMINACIÓN DEL pH}

El pH es el logaritmo de la reciproca de la concentración del ión hidrógeno o más precisamente, de la actividad del ión hidrógeno, en moles por litro. La escala práctica del $\mathrm{pH}$ comprende del cero (0), muy ácido, al 14 muy alcalino, con el valor medio de $\mathrm{pH} 7$ que corresponde a la neutralidad exacta a 25 ${ }^{\circ} \mathrm{C}$.

\section{MÉTODO ELECTROMÉTRICO}

\section{Equipo}

- Potenciómetro.

\section{Materiales y Accesorios}

- Vaso de $200 \mathrm{ml}$.

- Vaso de $100 \mathrm{ml}$.

- Termómetro de 0 a 100 oC.

- Papel "tisu".

\section{Reactivos}

- Agua destilada.

- Soluciones buffer $\mathrm{pH}=4, \mathrm{pH}=7, \mathrm{pH}=10$.

\section{Procedimiento}

Calibrar y estandarizar el potenciómetro con las soluciones buffer. Medir la temperatura de la muestra. Determinar el $\mathrm{pH}$.

Medición del pH : Operación.

1. Poner el interruptor en operación a standby; lavar los electrodos con agua destilada y secar con el papel tisu.

2. Medir la temperatura de la muestra y ajustar el dial de la temperatura. Colocar los electrodos en la solución de la muestra problema.

3. Poner el interruptor de operación a Read, el instrumento indicará el $\mathrm{pH}$ de la muestra problema.

(Por las diferencias entre las distintas marcas $y$ modelos comerciales de medidores de $\mathrm{pH}$, se debe seguir en cada caso las instrucciones de los fabricantes).

\section{DEMANDA BIOQUÍMICA DE OXÍGENO (DBO)}

Es la cantidad de oxígeno en $\mathrm{mg} / \mathrm{l}$ (ppm) necesarios para descomponer la materia orgánica presente en el agua por acción bioquímica aerobia.

\section{Materiales y Reactivos}

Los mismos utilizados en la determinación del oxígeno disuelto

\section{Procedimiento y Cálculos}

- Determinar el contenido de oxígeno de la muestra problema y luego de 05 días, de otra muestra semejante, pero conservada durante este tiempo en un frasco cerrado fuera del contacto del aire y a $20^{\circ} \mathrm{C}$.

La diferencia entre los 02 contenidos representa el DBO.

$$
\text { OD1 }- \text { OD5 }=\text { DBO }
$$

- Las aguas muy poluadas, que necesitan en los 5 dias cantidades de oxígeno mucho mayores a las presentes en la muestra, necesitan, para que la determinación pueda realizarse, añadir a una 
segunda muestra una cantidad de agua destilada saturada de oxígeno, a fin de que quede en la muestra algo de oxigeno después de los 05 dias.

El cálculo se efectúa como sigue:

$$
\text { OD } 1-\text { OD } 5=\text { DBO }
$$

donde:

$O D 1=$ Es el oxigeno disuelto en la muestra diluida después de la pre-aereación.

$O D 5=$ Es el oxígeno disuelto en la muestra diluída después de los 05 dias de incubación.

\section{DEMANDA QUIMICA DE OXÍGENO (DQO)}

La Demanda Quimica de oxígeno, es la cantidad de oxígeno consumido por las materias existentes en el agua y oxidables en condiciones operatorias definidas.

\section{Método}

Determinación del oxígeno consumido con permanganato de potasio.

\section{Materiales y Equipo}

- Beakers de 200 o $300 \mathrm{ml}$.

- Bureta de $25 \mathrm{ml}$.

- Pipetas de 5 y $10 \mathrm{ml}$.

- Cocinilla.

\section{Reactivos}

- Sal de Mohr. Disolver $20 \mathrm{~g}$. de Sulfato ferroso en 10 cc. de ácido sulfúrico puro y añadir agua destilada en cantidad suficiente para completar a 01 litro.

- Acido sulfúrico puro.

- Permanganato de Potasio N/80.

\section{Procedimiento}

- Filtrar la muestra para evitar el ingreso de materia orgánica no disuelta. Tomar $100 \mathrm{ml}$ de este filtrado en un beaker.

- Añadir a la muestra $5 \mathrm{ml}$ de ácido sulfúrico al $50 \%$ y $10 \mathrm{ml}$ de Permanganato de Potasio N/80.

- Hervir por 10 minutos. Se considera solamente el periodo de ebullición y no el calentamiento previo.

- Enfriar hasta temperatura ambiente y agregar $5 \mathrm{ml}$ de ácido sulfúrico quimicamente puro, más $5 \mathrm{ml}$ de sal de Mohr.

- Titular con Permanganato de Potasio N/80 hasta obtener una coloración rosa persistente.Anotar el gasto previamente.
- Efectuar el procedimiento mencionado con la muestra en blanco, de agua destilada.

\section{Cálculos}

$\mathrm{n}$ : cc.de gasto en la muestra problema.

$n^{\prime}$ : cc.de gasto en "blanco" con agua destilada.

Gasto Real $=n-n^{\prime}$

$$
\mathrm{O} 2 \mathrm{ppm}=\frac{\text { Gasto real } \times 0.0125 \times 8000}{\text { Volumen de Muestra }}
$$

\section{DETERMINACION DE DUREZA}

\section{MÉTODO COMPLEXOMÉTRICO}

Se llama dureza a la suma de iónes alcalinotérreos como $\mathrm{Ca}^{+2}, \mathrm{Mg}^{+2}$ fijados en forma de carbonatos, sulfatos, cloruros, nitratos, fosfatos, etc. Para cuya cuantificación se emplea el etilendiamino tetracético, agente quelatizante que forma complejos hidrosolubles con los iónes $\mathrm{Ca}$ y $\mathrm{Mg}$.

\section{Reactivos}

1. Solución amortiguadora. $\mathrm{pH}=10$

Pesar $67.5 \mathrm{~g}$ de $\mathrm{ClNH} 4+570 \mathrm{ml}$ de $\mathrm{NH} 4 \mathrm{OH}$ concentrado y diluir a $1000 \mathrm{ml}$ con agua destilada.

2. Solución de EDTA $0.01 \mathrm{~N}$ : Pesar $1.8612 \mathrm{~g}$ de EDTA, agregar $0.05 \mathrm{~g}$ de $\mathrm{MgCl} 2.6 \mathrm{H} 2 \mathrm{O}$ y diluir con agua destilada hasta $1000 \mathrm{ml}$.

3. Indicador Negro de Eriocromo T. Pesar NET $0.5 \mathrm{~g}$ y mezclarlo intimamente con $100 \mathrm{~g}$ de $\mathrm{NaCl}$.

\section{Material}

-Fiolas, vasos, matraces, bureta.

\section{Procedimiento}

Tomar $25 \mathrm{ml}$ de muestra, agregar $02 \mathrm{ml}$ de solución amortiguadora $\mathrm{pH}=10$, luego agregar $50 \mathrm{ug}$ de NET y aparecerá una coloración rojo vino, luego titular con EDTA hasta que aparezca un color azul.

\section{Cálculos}

Dureza Total $\mathrm{mg} / \mathrm{l}=\frac{\text { Gasto } \times \mathrm{N} \times \mathrm{Fc} \times 50 \times 1000}{\mathrm{ml} \text { de muestra }}$

Donde :
$\mathrm{N}$ : Normalidad de la solución de EDTA.
fc : Factor de corrección de la solución de EDTA.

\section{DETERMINACIÓN DE CALCIO EN EL AGUA}

\section{Reactivos}

1. Solución de Hidróxido de Sodio 1,0 N: pesar 
aproximadamente $40 \mathrm{~g}$ de $\mathrm{NaOH}$ puro y diluir en agua destilada hasta completar 1,0 litro.

2. Indicador de Calcio: mezclar $0,2 \mathrm{~g}$ de Murexida (tambien llamado Purpurato de Amonio) con $100 \mathrm{~g}$ de Cloruro de Sodio. Mezclar bien para uniformizar el compuesto.

3. Solución de E.D.T.A.: disolver $4,0 \mathrm{~g}$ de Disodium Dihidrogen ethilenediamine tetracetate (EDTA) y $0,1 \mathrm{~g}$ de Cloruro de Magnesio ( $\mathrm{MgCl} 2.6 \mathrm{H} 2 \mathrm{O})$, en $750 \mathrm{ml}$ de agua destilada. Completar a 1,0 litro en una fiola.

4. Patrón de Cloruro de Calcio: disolver $1,0 \mathrm{~g}$ de $\mathrm{CO} 3 \mathrm{Ca}$ puro en $10 \mathrm{ml}$ de $\mathrm{HCl}$ 1:10 y diluir con agua destilada hasta completar 1,0 litro. $1 \mathrm{ml}=1 \mathrm{mg}$ de $\mathrm{CaCO} 3$.

\section{Procedimiento}

1. Medir $50 \mathrm{ml}$ de agua a ser analizada y colocarla en un frasco erlenmeyer.

2. Adicionar $2 \mathrm{ml}$ de solución de $\mathrm{NaOH} 1 \mathrm{~N}$. Agitar.

3. Adicionar $0,2 \mathrm{~g}$ de indicador de Calcio y agitar.

4. Si el Calcio está presente, un color rosado se desarrollará.

5. Titular la muestra con una solución EDTA, agitando constantemente, hasta que el color rosado vire a violeta.

\section{Cálculo de los resultados}

Multiplicar los $\mathrm{ml}$ de EDTA gastados en la titulación por $20=\mathrm{Ca}$ (ppm de $\mathrm{CaCO} 3)$.

ml EDTA gastados $\times 20=\mathrm{Ca}(p p m$ de $\mathrm{CaCO} 3)$.

\section{DETERMINACIÓN DE COMPUESTOS DE NITRÓGENO}

-Determinación de Nitratos.

-Determinación de Amonio.

\section{DETERMINACIÓN DE NITRATOS EN NITRÓGENO}

Hay muchas formas de nitrógeno, pero los nitratos son los más importantes. Las investigaciones que se vienen realizando, vienen demostrando que la producción máxima de fitoplancton es acompañada por una disminución rápida de los nitratos, en las muestras donde es verificada tal producción.

\section{Método}

\section{Método del Ácido Fenoldisulfónico}

Al adicionar $2 \mathrm{ml}$ de Acido Fenoldisulfónico a $100 \mathrm{cc}$ de muestra, en presencia de $\mathrm{NH} 4 \mathrm{OH}(1: 1)$, se produce una coloración amarilla, cuya intensidad depende de la concentración de los nitratos,si se detecta cloruro en la muestra a ser analizada y tiene un valor superior a $30 \mathrm{ppm}$, se deberá tratar la muestra con algunas gotas de solución de Sulfato de Plata (5\%) para lograr el precipitado de los cloruros. Filtrar luego la muestra y proceder al análisis.

\section{Reactivos}

1. Solución de Acido Fenoldisulfónico: disolver $25 \mathrm{~g}$ de Fenol puro en $150 \mathrm{ml}$ de ácido sulfúrico concentrado, adicionar $75 \mathrm{ml}$ de ácido sulfúrico fumante (13-15\% de SO3) y calentar por 2 horas. Guardar en frasco oscuro.

2. Solución patrón de Nitrato: disolver $0,607 \mathrm{~g}$ de nitrato de sodio puro en un litro de agua destilada exenta de nitratos. Evaporar $50 \mathrm{ml}$ de esta solución en un disco de porcelana. Cuando esté fria, tratar con $2 \mathrm{ml}$ de ácido fenoldisulfónico. Mezclar bien con una bagueta o asta de vidrio para garantizar una información perfecta de la mezcla. Diluir en agua destilada hasta completar $500 \mathrm{ml}$. Un $(1,0)$ $\mathrm{ml}$ de esta solución es equivalente a $0,01 \mathrm{mg}$ de nitrógeno como nitrato (esta solución no se altera).

3. Solución de Hidróxido de Amonio: diluir $500 \mathrm{ml}$ de $\mathrm{NH} 4 \mathrm{OH}$ en agua destilada hasta completar un litro.

\section{PREPARACIÓN DE LOS PATRONES}

\begin{tabular}{|c|c|c|}
\hline NITRATO PATRÓN & $\begin{array}{c}\text { DILUCIÓN } \\
\mathrm{ml}\end{array}$ & $\begin{array}{c}\text { EQUIVALENTE EN } \\
\mathrm{ppm}\end{array}$ \\
\hline 0,5 & 100 & 0,05 \\
1,0 & 100 & 0,10 \\
2,0 & 100 & 0,20 \\
5,0 & 100 & 0,50 \\
10,0 & 100 & 1,00 \\
\hline
\end{tabular}

Para hacer esta bateria, colocar en tubos Nessler o Erlenmeyer, la cantidad de nitrato patrón descrita y adicionar $\mathrm{NH} 4 \mathrm{OH}$ hasta completar $100 \mathrm{ml}$. Se desarrollará una coloración amarilla y su intensidad será mayor donde la concentración de nitrato es mayor (NO3).

\section{DETERMINACIÓN DE NITRATOS EN LA MUESTRA}

1. Filtrar $100 \mathrm{ml}$ de la muestra de agua y colocar en una placa de porcelana.

2. Calentar hasta evaporar.

3. Cuando se enfrie adicionar $2 \mathrm{ml}$ de la solución de ácido fenoldisulfónico. Mezclar con bagueta o asta de vidrio. 
4. Diluir con agua destilada hasta completar $10 \mathrm{ml}$.

5. Adicionar $\mathrm{NH} 4 \mathrm{OH}$ (Hidróxido de Amonio) 1:1, hasta que el máximo color se desarrolle. Tranferir a un tubo Nessler de $100 \mathrm{ml}$ y adicionar agua destilada hasta completar los $100 \mathrm{ml}$.

6. Comparar la muestra con los colores patrones y estimar la cantidad de nitratos en nitrógeno.

\section{DETERMINACIÓN DE AMONIO}

\section{Material}

- Probeta de $50 \mathrm{ml}$.

- Frasco Erlenmeyer.

- Pipeta de I ml.

- Tubos de Nessler.

\section{Reactivos}

1. Solución Patrón de Cloruro de Amonio (5 ppm de N):

- Pesar exactamente 1,905 g de Cloruro de Amonio puro $(\mathrm{NH} 4 \mathrm{Cl})$, diluir con agua destilada y completar a un litro.

- Tomar $10 \mathrm{ml}$ de la solución descrita y completar a 1,0 litro con agua destilada. Esta dilución contiene 5 ppm de $\mathrm{N}$ en amonio.

2. Reactivo de Nessler:

- Disolver $100 \mathrm{~g}$ de $\mathrm{Hgl} 2$ y $70 \mathrm{~g}$ de $\mathrm{KI}$, en $200 \mathrm{ml} \mathrm{de}$ agua destilada.

- Disolver $160 \mathrm{~g}$ de $\mathrm{NaOH}$ en $500 \mathrm{ml}$ de agua destilada. Dejar enfriar.

- Adicionar lentamente la solución de $\mathrm{HgI} 2+\mathrm{KI}$ en la solución de $\mathrm{NaOH}$.

- Completar a un litro con agua destilada.

- Guardar en frasco oscuro.

\section{Determinación}

1. Tomar $50 \mathrm{ml}$ de la muestra y colocar en un frasco Erlenmeyer.

2. Adicionar $2 \mathrm{ml}$ del reactivo de Nessler. Dejar en reposo por 10 minutos hasta que se desarrolle totalmente el color. Llevar la muestra a un colorimetro y hacer la lectura.

La determinación cuantitativa de amonio puede ser hecha con una bateria de colores preparados de la siguiente manera:

\begin{tabular}{|c|c|}
\hline $\begin{array}{c}\text { VALORES DE } \\
\text { PPM EN N }\end{array}$ & $\begin{array}{c}\text { DILUCIONES DE SOL.PATRON DE CLNH4 QUE } \\
\text { CONTIENE 5PPM, HASTA COMPLETAR 50 ML } \\
\text { CON AGUA DESTILADA. }\end{array}$ \\
\hline 0,10 & 1,0 \\
0,25 & 2,5 \\
0,50 & 5,0 \\
0,75 & 7,5 \\
1,00 & 10,0 \\
\hline
\end{tabular}

Para cada tubo de Nessler patrón, adicionar $2 \mathrm{ml}$ del reactivo de Nessler. Dejar en reposo por 10 minutos para que se desarrolle completamente el color. Las muestras analizadas entonces se pueden comparar con la bateria de colores y estimar de esta manera la concentración de amonio en $\mathrm{N}$.

\section{DETERMINACIÓN DE CLORUROS EN EL AGUA}

\section{METODO DE MOHR}

\section{Reactivos}

1. Solución de Nitrato de Plata $0,0141 \mathrm{~N}$ : pesar $2,4 \mathrm{~g}$ de $\mathrm{AgNO}_{3}$ y diluir en agua destilada hasta completar un litro. Guardar en frasco oscuro.

2. Solución indicadora de Cromato de Potasio al $5 \%$ : pesar $5 \mathrm{~g}$ de $\mathrm{K} 2 \mathrm{CrO} 4$ y diluir en agua destilada hasta completar $100 \mathrm{ml}$.

\section{Procedimiento}

1. Tomar $10 \mathrm{ml}$ de la muestra a ser analizada y completar a $50 \mathrm{ml}$ con agua destilada y colocar en un frasco erlenmeyer.

2. Agregar $1 \mathrm{ml}$ de la Solución Indicadora de Cromato de Potasio.

3. Titular con la solución de $\mathrm{AgNO} 3$ hasta que el color amarillo vire a rojo ladrillo.

\section{Cálculo de concentración de Cloruro en ppm.}

$C l=\frac{1000(\mathrm{~N}-0,2)}{2 \mathrm{~A}}$

$\mathrm{N}=$ Gasto de AgNO3.

$A=$ Cantidad de muestra de agua analizada.

\section{DETERMINACIÓN DE SODIO Y POTASIO}

\section{Principio}

El sodio y el potasio son medidos Flamafotométricamente contra series standard de un elemento solo, soluciones acuosas, usando una llama 
de aire propano como fuente de energia para excitar a los átomos.

\section{Equipos}

- Fotómetro de llama.

\section{Reactivos}

1. Solución patrón de Potasio de 100 ppm: Disolver $0.1907 \mathrm{~g}$ de $\mathrm{KCl}$ secado a $105 \mathrm{oC}$ en un frasco volumétrico de $1000 \mathrm{ml}$ y completarlo a la marca con agua.

2. Solución patrón de Sodio de 100 ppm : disolver $0.2541 \mathrm{~g}$ de $\mathrm{NaCl}$ secado a $105 \mathrm{oC}$ en un frasco volumétrico de $1000 \mathrm{ml}$ y completarlo a la marca con agua.

\section{Material de muestra}

- Una alicuota de agua.

\section{Procedimiento}

1. Preparar separadamente (para sodio y potasio) series standard de :

$0,10,20,40,60,80,100 \mathrm{ppm}$ pipeteando (para cada caso) $0,1,2,3,4,6,8,10 \mathrm{ml}$., de la solución standard de $100 \mathrm{ppm}$ dentro de tubos de prueba y, llevar a $10 \mathrm{ml}$ con agua destilada.

Muestras : medir directamente.

2. Calibrar el Fotómetro de llama, medir las series standard y muestras de acuerdo a las instrucciones para el uso del instrumento.

3. En caso de que los extractos sean demasiado concentrados, diluir en tubos de prueba y repetir la medición.

4. Anotar en las hojas de trabajo las diluciones realizadas.

5. Chequear el instrumento para el impulso entre las lecturas sucesivas de un grupo de determinaciones y también al final de una serie con uno de los standars, usualmente el standard de 100 ppm.

\section{Cálculos}

- Construir la curva calibradora, ploteando en un papel de gráfico, las lecturas contra la concentración de series standard.

- Determinar la cantidad de sodio y de potasio de las muestras por medio de sus lecturas y corregir el blanco.

\section{ORTOFOSFATOS}

Son compuestos del fósforo que pueden hallarse en variadas formas, ya sea en solución como materia orgánica, como partículas de materia o en solución como iónes inorgánicos (ortofosfatos), siendo éstos últimos los más valiosos como nutrientes para el crecimiento de las plantas y animales.

\section{Fundamento}

Este método consiste en hacer reaccionar la muestra de agua con un reactivo que contiene ácido molibdico, ácido ascórbico y un antimonio trivalente. El complejo resultante, ácido heteropolar, es reducido para dar una coloración azul, que es proporcional a la concentración de fosfato de la muestra.

\section{Materiales}

- Vasos de $100 \mathrm{ml}$.

- Erlenmeyers de 100 y $50 \mathrm{ml}$.

- Fiolas de $50 \mathrm{ml}$.

- Pipetas de 5 y $10 \mathrm{ml}$.

\section{Reactivos}

1. Solución de Molibdato de Amonio : disolver $15 \mathrm{~g}$ de Heptamolibdato de Amonio en $500 \mathrm{ml}$ de agua destilada. Almacenar en botellas de plástico fuera del alcance de la luz. La solución es indefiniblemente estable.

2. Solución de $\mathrm{H} 2 \mathrm{SO} 4$ : adicionar $140 \mathrm{ml}$ de $\mathrm{H} 2 \mathrm{SO} 4$ concentrado $(\mathrm{d}=1.82 \mathrm{~g} / \mathrm{cm})$ a $900 \mathrm{ml}$ de agua destilada. Enfriar la solución y almacenar en botella de vidrio.

3. Solución de ácido ascórbico : disolver $27 \mathrm{~g}$ de ácido ascórbico en $500 \mathrm{ml}$ de agua destilada. La solución no debe guardarse muchos dias.

4. Solución de Tartrato de Antimonio y Potasio : disolver $0.34 \mathrm{~g}$ de Tartrato de antimonio en $250 \mathrm{ml}$ de agua destilada, calentar si es necesario. Guardar en un frasco de vidrio o plástico. La solución es estable por muchos meses.

5. Mezcla de reactivos:

\begin{tabular}{|c|c|c|c|c|c|}
\hline & & \multicolumn{4}{|c|}{ NUMERO DE MUESTRAS } \\
\hline \multirow{2}{*}{$\begin{array}{l}\mathrm{R} \\
\mathrm{E} \\
\mathrm{A}\end{array}$} & & 30 & 50 & 80 & 100 \\
\hline & Molib.Amonio & $30 \mathrm{ml}$ & $50 \mathrm{ml}$ & $80 \mathrm{ml}$ & $100 \mathrm{ml}$ \\
\hline C & Sol.H2SO4 & $7.5 \mathrm{ml}$ & $125 \mathrm{ml}$ & $200 \mathrm{ml}$ & $250 \mathrm{ml}$ \\
\hline i & Ac.Ascórbico & $30 \mathrm{ml}$ & $50 \mathrm{ml}$ & $80 \mathrm{ml}$ & $100 \mathrm{ml}$ \\
\hline $\begin{array}{l}V \\
0\end{array}$ & & $1.62 \mathrm{~g}$ & $2.70 \mathrm{~g}$ & $4.32 \mathrm{~g}$ & $5.40 \mathrm{~g}$ \\
\hline s & Tartrat.Antim & $15 \mathrm{ml}$ & $25 \mathrm{ml}$ & $40 \mathrm{ml}$ & $50 \mathrm{ml}$ \\
\hline
\end{tabular}




\section{Procedimiento}

1. Para $50 \mathrm{ml}$ de muestra adicionar $5+-0.25 \mathrm{ml}$ de la mezcla de reactivos. Mezclar.

2. Después de 5 minutos y de preferencia dentro de 2 a 3 horas medir la extinción de la solución en una celda de $5 \mathrm{~cm}$ frente a agua destilada, en una longitud de onda de $720 \mathrm{~nm}$.

3. Corregir la extinción medida restándole del blanco. El blanco es una muestra de $50 \mathrm{ml}$ de agua destilada, tratada en la misma forma que las otras.

4. La concentración de fosfato es leída del gráfico obtenido de las series standard.

\section{Las series Standard:}

Solución Stock de Fosfato : pesar $4.393 \mathrm{~g}$ de Potasio hidrógeno fosfato previamente secado en un desecador y disolverlo en agua destilada en un fiola de 1.0 litro, luego adicionar $1.0 \mathrm{ml}$ de $\mathrm{H} 2 \mathrm{SO} 4$ concentrado y enrazar hasta la marca con agua destilada.

La solución contiene $1 \mathrm{mg}-\mathrm{P} / \mathrm{ml}$.

\section{REFERENCIAS BIBLIOGRÁFICAS}

AMERICAN PUBLIC HEALTH ASSOCIATION-APHA-(1981). Standart Methods for the examination of water and waste water. 16 ed. Washington.

AQUINO PORTAL, ROSA (1989). Métodos para análisis de aguas suelos y residuos sólidos. 1era. edición. CONCYTEC.

CHAPMAN H. PARKER F. PRATT (1988). Métodos de Análisis para suelos, plantas y aguas. 6ta. edición. Editorial Trillas S.A. Mexico.

LAEVASTU, T.(1971). Manual de Métodos de Biologia Pesquera. Editorial Acribia. Zaragoza. España.

SCHWOERBEL, J.(1970). Methods of Hydrobiology Freshwater Biology. Pergamen Press
De la solución stock de fosfato preparar una solución de trabajo de $1 \mathrm{ug}-\mathrm{P} / \mathrm{ml}$.

La solución de trabajo es diluida con agua destilada como indica la siguiente tabla:

\begin{tabular}{|l|r|r|r|r|}
\hline $\begin{array}{l}\text { ml de Solución de trabajo para } \\
\text { diluirse a } 50 \mathrm{ml} \\
\text { Correspondiente a ug-P/l }\end{array}$ & 0 & 1.0 & 2.0 & 5.0 \\
\hline
\end{tabular}

La serie standard es tratada en la misma forma como las muestras. Después de 5 minutos, la extinción es medida en $720 \mathrm{~nm}$. Las extinciones obtenidas de la serie standard son graficadas en un sistema lineal de coordenadas (papel milimetrado) vs. la concentración, deberá obtenerse una linea recta en el gráfico.

\section{Expresión de los resultados}

En las mismas condiciones de utilización, la curva da directamente el contenido en fósforo, expresado en microgramos por litro.

MERK (1985). Análisis del Agua. Edición en Español.

RODIER J. Análisis de Agua. 1 ra Ed. Ediciones Omega. Barcelona. España.

PERSONAL DEL LABORATORIO DE SALINIDAD DE LOS SUELOS DE EEUU DE AMERICA.(1980). Suelos Salinos y Sódicos. Editorial Limusa. Mexico.

UNIVERSIDAD NACIONAL AGRARIA «UNA» (1982). Manual de Análisis de Suelos, Tejido vegetal, Aguas y Fertilizantes. Lima. Perú.

WETZEL G. ROBERT (1981). Limnologia. Ediciones Omega S.A. Barcelona. España. 